\title{
An overview of teacher training programs in educational robotics: characteristics, best practices and recommendations
}

\author{
Despoina Schina $^{1}$ (D) $\cdot$ Vanessa Esteve-González $^{1}$ (D) Mireia Usart $^{1}$ (D)
}

Received: 25 May 2020 / Accepted: 27 October 2020/ Published online: 16 November 2020

(C) The Author(s) 2020

\begin{abstract}
The emergence of Educational Robotics (ER) and its rapid spread across all levels of education in recent years has drawn attention to the need for further training in this discipline. In this study we discuss the panorama of teacher training research in ER and make recommendations for institutions that intend to implement ER teacher training programs. We explore three databases that include publications in ER teacher training and select 38 publications for analysis. We discuss these publications with special emphasis on requirements, durations, trainer and trainee profiles, pedagogical approaches and best practices. Our main findings are the lack of uniformity regarding the duration and requirements of training programs and the fact that information on trainer and trainee profiles is not always documented. ER teacher training programs are often not founded on theory. When they are based on pedagogical principles, however, these are usually constructivism/constructionism, inquiry-based learning or projectbased learning. The most prominent best practices for ER teacher training fall into five categories: collaboration, materials, pedagogy, practice and feedback/support. Our recommendations will help to improve the content, structure and implementation of future ER teacher training programs and the reliability and generalizability of research results and design.
\end{abstract}

Keywords Educational robotics · Teacher training - Improving classroom teaching · Digital technologies

\footnotetext{
Despoina Schina

despoina.schina@urv.cat

Vanessa Esteve-González

vanessa.esteve@urv.cat

Mireia Usart

mireia.usart@urv.cat
}

Extended author information available on the last page of the article 


\section{Introduction}

Introducing digital technologies (DT), digital skills and coding into education is not just a recommendation but a requirement established by the European Union with which educational institutions in the EU must comply. According to the report "A Comprehensive European Industrial Policy on Artificial Intelligence and Robotics" (Committee on Industry, Research and Energy 2019), instructional programs must be adapted, new learning paths must be created, and new technologies must be integrated. The report puts special emphasis on developing digital skills, including coding that should be integrated into teaching and teacher training across all educational levels - from preschool education to life-long learning. Educational Robotics (ER) is identified as an educational resource through which objectives associated with the development of digital skills, including coding, can be accomplished. Moreover, ER promotes student engagement and learning in STEM subjects (Science, Technology, Engineering and Mathematics) (Taylor 2016), positively affects students' personal development (Sisman and Kucuk 2019), and promotes understanding of STEM concepts (Nugent et al. 2012).

ER is a way to approach the development of students' digital skills. However, the question remains whether teaching staff can live up to expectations and satisfy the requirements of introducing this new educational resource into their regular teaching activities to promote the development of students' digital skills, including coding. Chambers and Carbonaro (2003) pointed out that integrating robotics technologies into schools was a challenge for the educational community and even today educators seem to find this task demanding. Sisman and Kucuk (2019), for example, reported that many teachers are unaware of the benefits of ER and that those teachers who are remain unprepared to teach robotics. This lack of readiness on the part of teachers regarding the use of robotics in their classrooms may be due to the lack of specialized training programs in educational institutions, the inadequate content of existing training programs, or other reasons. Major et al. (2011) highlighted the importance of providing pre-service teachers with specialized training to enable them to teach coding adequately and feel more self-confident in this area. Our study starts from the view that teacher training is hugely important for successfully integrating ER into the curriculum since it affects students' acquisition of digital skills, including coding. However, successful ER integration requires teachers to understand its potential benefits and know what are the best pedagogical approaches for implementing ER activities in class (Bers et al. 2013). As we discuss later, the pedagogical theory of constructivism/constructionism is closely related to ER (Tochácek et al. 2016). To enhance research in the field of ER teacher training, in this study we examine the teacher training programs documented in the literature, showcase the characteristics of implemented programs and their best practices, and make several recommendations for future ER teacher training programs and research.

\section{Method}

This literature review was conducted in the following three review phases based on Kitchenham (2004): planning, conducting and reporting. These phases will be further explained in the following sections. 


\subsection{Planning the review}

First we examined the literature in the rapidly growing field of educational robotics and found several literature review studies. Benitti (2012), for example, explored the educational potential of robotics in schools, identified the contribution made by integrating robotics as an educational tool in schools, and explored its effectiveness. Bascou and Menekse (2016), for their part, divided research studies on K-12 robotics into several categories and presented the state of research in the field. Later, Spolaôr and Benitti (2017) studied systematically relevant educational robotics experiences with theoretical support on tertiary education. A more recent literature review by Pedersen et al. (2020) explored the focus, findings and design of research studies conducted with commercially available educational robotics and made several recommendations on how future studies in the field could be designed and conducted.

Our literature review stems from Benitti's (2012) suggestion on investing in ER teacher training and seeks to expand the classification of ER research studies made by Bascou and Menekse (2016). This proposed a classification, identified common themes in the literature, systematically organized the studies, and investigated the implementation of robotics in K-12 STEM education. One category was "professional, curricular, and pedagogical development", which comprised studies related to ER instruction. When Bascou and Menekse analyzed the studies in this category, they found that most of them evaluated teacher training workshops. However, most of these studies were not based on quantitative analysis but on qualitative teacher feedback or surveys. Bascou and Menekse therefore suggested that researchers should use more rigorous methods of analysis and conduct longitudinal studies. Our literature review further explores the current bibliography on teacher training programs in educational robotics in order to provide the educational community with insight and recommendations for ER teacher education. More precisely, the aim of this literature review is to structure and organize research initiatives exclusively in the field of ER teacher training where, to our knowledge, there are no prior results. This systematic review is structured around the research questions defined below.

\subsubsection{Research questions}

- Research Question 1: What are the characteristics of ER teacher training programs in terms of requirements, duration, trainer and trainee profiles and pedagogical approach?

- Research Question 2: What best practices for ER teacher training programs are documented in the literature?

\subsubsection{Study search strategy}

The following search string was applied to ERIC, Scopus and Web of Science, all of which contain peer-reviewed, high-quality journal articles, reports, conference papers, and books on the Educational Sciences. The search was restricted to study title, abstract and keywords. Since the search string was long, it was split into shorter strings and combined partial results for databases with size restrictions. The search string was: 
("robot" OR "robotic" OR "lego") AND ("teacher training" OR "teacher education" OR "teacher development" OR "pre-service teacher" OR "in-service teacher" OR "trainee teacher" OR "practising teacher" OR "practicing teacher").

\subsubsection{Selection and exclusion criteria}

The selection and exclusion criteria for the articles included in our systematic literature review are shown in Table 1 . When a study met at least one exclusion criterion, it was removed from the review. No exclusion criteria were related to the article's date of publication. The aim was to conduct an extensive review and examine whether changes have occurred in ER training since the emergence of ER.

In total, 38 publications were included in the literature review. The selection process is presented in detail in Section 2.2 (Conducting the review).

\subsubsection{Extracted information and synthesis strategy}

The information extracted from 38 publications was incorporated into a database under the following three main themes: information about the publication itself, i.e. title, date and authors; the characteristics of the teacher training program (duration, requirements, trainer and trainee profile, and pedagogical approach) (see first research question); the authors' best practices in ER teacher training studies (see second research question). A qualitative synthesis was applied to answer the research questions based on the information in the database.

Table 1 Exclusion and Selection Criteria

\begin{tabular}{l} 
Exclusion criteria \\
\hline EC1: The publication was considered out of context \\
$\begin{array}{l}\text { (e.g. the study examined primary school } \\
\text { pupils' ER learning). }\end{array}$
\end{tabular}




\subsection{Conducting the review}

\subsubsection{Sample}

This study was conducted between May and July 2019. In total, 242 resources were found. Most of these (47\%) were from the SCOPUS database, with publication dates ranging from 1986 to 2019. Publications from the Web of Science represented 29\% of our sample and those from ERIC represented 24\%. Publication dates of the articles from the latter two resources ranged from 1987 and 2019.

\subsubsection{Publication selection process}

The articles were selected in three phases (see Fig. 1). In the first phase, duplicate resources were deleted. In the second phase, we selected suitable publications according to whether they satisfied the selection criteria (Table 1) by examining only their title and abstract. In the third phase, we selected the remaining publications according to the selection criteria by examining the full-length publication. Before step 1 we had agreed on the selection and exclusion criteria and on which information was to be extracted from the publications. This concerned the content and structure of the teacher training program, (including the requirements, duration and pedagogical approach, etc.) and the profiles of the trainers and trainees. The first author conducted the publication selection process and extracted the information from the selected publications. Simultaneously, her work was being constantly reviewed by the second and third authors. Any discrepancies among the researchers regarding the selection process and information extraction were discussed and $100 \%$ consensus was reached. In step 1, the main information about the authors, publication date and publication source was extracted from the article and any duplicate publications were removed. Out of 242 publications from the three databases, $42(17 \%)$ were duplicates. After removing these duplicates, we selected 200 publications to proceed to the following step. In step 2, the title and abstract of these 200 publications were studied and, based on the exclusion criteria outlined in Section 2.1.3, the publications were filtered. In total, 94 publications (almost half the total number of publications in this step) were excluded, which left 106

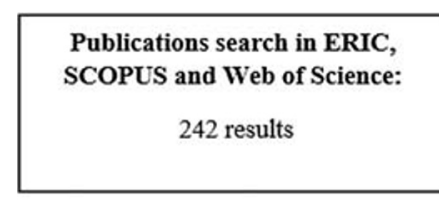

Step 3. Removal of publications based on full-text:

38 publications selected

68 publications removed
Step 1. Removal of duplicate publications:

200 publications selected

42 duplicates removed

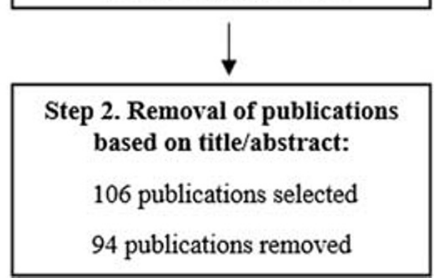

Fig. 1 Summary of the publication selection process 
publications for step 3. In step 3, the remaining articles were examined and 38 publications were finally selected for the literature review.

A total of 38 publications were selected for this review (16\% of the initial results). Several publications in steps 1, 2 and 3 were excluded based on the exclusion criteria outlined in Section 2.1.3. In Fig. 2 the publications are displayed by status, i.e. selected publications, duplicates and excluded publications by exclusion criterion. The most frequent exclusion criterion, which was applied to $33 \%$ of publications, was EC1 ("The publication was considered out of context"). EC3 ("The publication is not in English") and EC4 ("The publication is not in the correct format") each accounted for $11 \%$ of exclusions, which suggests that these criteria were both fairly common. While conducting this review, we found that many publications were in Korean and so were excluded. In Section 3 we present the results of this review in accordance with our research questions.

\section{Results \& discussion}

\subsection{Research question 1: What are the characteristics of ER teacher training programs in terms of requirements, duration, trainer and trainee profiles and pedagogical approaches?}

\subsubsection{Requirements for the completion of ER training}

The requirements set by training programs have a direct impact on their participants' involvement with ER, their time commitment to ER and, therefore, their learning. Depending on the requirements of the training programs, the participants' learning experience may be different and the learning outcomes may change. Surprisingly, in

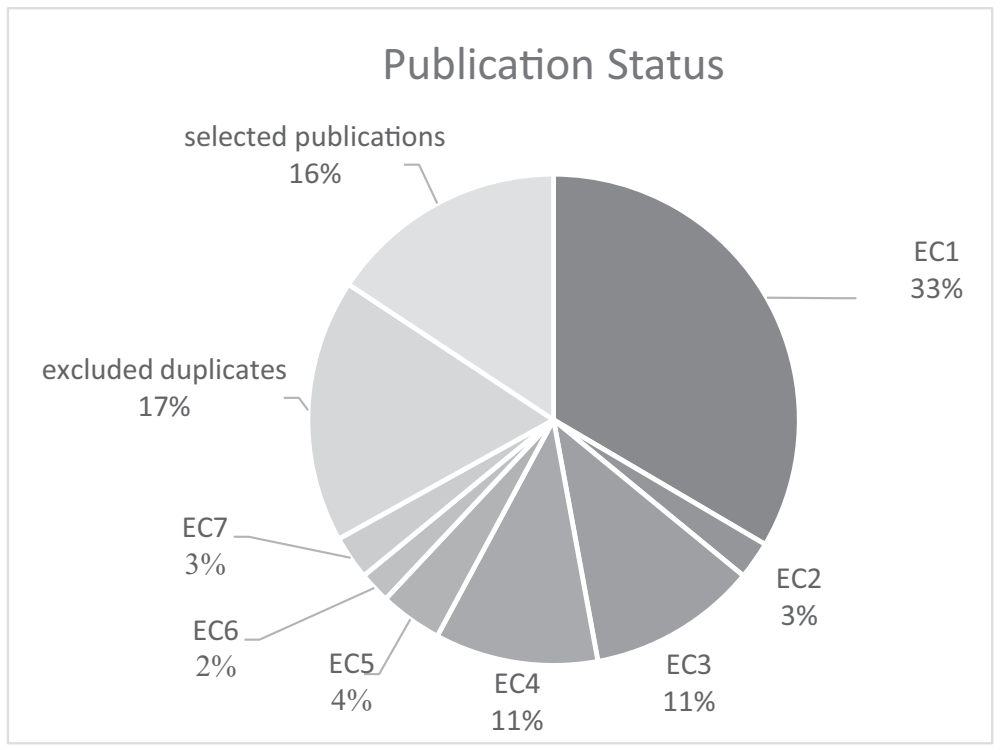

Fig. 2 Publications selected and rejected, by exclusion criterion 
$50 \%$ of the research studies (19 publications) we examined, there are no requirements for completion other than attendance. The remaining publications do set requirements for the completion of their training programs, however: 11 publications (29\%) set a final project and $8(21 \%)$ require teaching practice (see Fig. 3). The training programs shown in Fig. 3 also indicate whether the programs are for pre-service teacher training, in-service teacher training, or mixed-status teacher training. In-service teacher training programs take place either in their own educational institutions or in state teacher training institutions. Pre-service teacher training programs, on the other hand, are mainly conducted as part of a university Bachelor's or Master's degree, while mixedstatus teacher training programs include pre-service and in-service teachers in joint training programs. The mixed training programs may also enable participants with different profiles (in terms of teaching experience, age and familiarity with technology, etc.) to get involved with ER in the same sessions. This may have considerable benefits for both pre-service and in-service teachers since they can share their different experience and perspectives.

Many studies in our sample present training programs with no requirements (see Table 2). The absence of any requirements for a training program raises questions about participants' learning and achievement of the programs' learning and research objectives. For example, Santos et al. (2016) studied the effectiveness of the training delivered with no assignment, project or teaching practice required from participants. Here, the lack of training requirements may cast doubt on how the effectiveness of the training is measured and, therefore, on the achievement of the research objectives. The absence of a final project or teaching practice requirement impairs the accurate measurement of a training program's effectiveness. Interestingly, some nonrequirement studies reported that participants were encouraged to incorporate the knowledge they had acquired on their program into their classroom teaching or curricular teaching practice (Alimisis 2014; Kay and Moss 2012; von Wangenheim et al. 2017), even though it was not a requirement for the completion of their training.

In the case of studies of training programs with final project requirements, this final project could be to design a robot, create a program or design instructional material that such as a lesson plan. The most common requirement is to design instructional material. To be more precise, a lesson plan may be assigned as a follow-up activity after a training session (Nagchaudhuri and Mitra 2007) or the participants may be asked to create their own lesson plans and then discuss and/or present them in class (Kim et al.

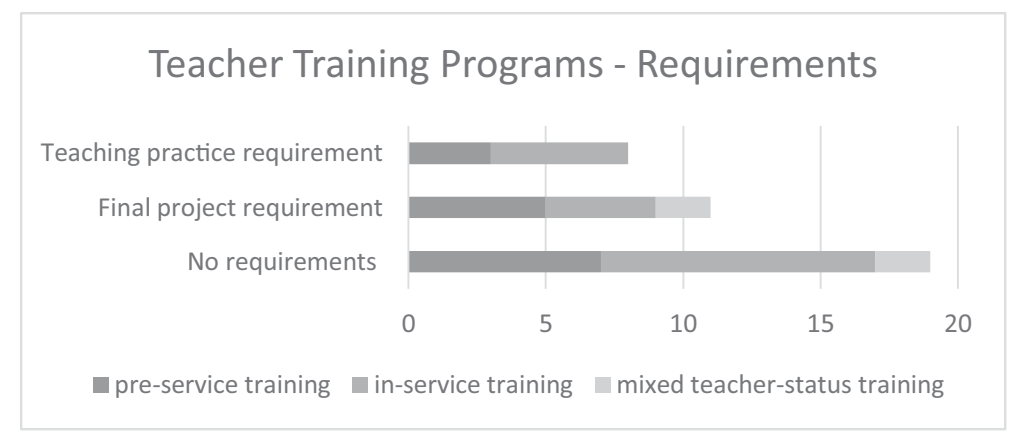

Fig. 3 Requirements of teacher training programs 
Table 2 Classification of the training programs

\begin{tabular}{|c|c|c|}
\hline Category & Sub-category & Publications \\
\hline \multirow[t]{3}{*}{$\begin{array}{l}\text { Teacher training } \\
\text { programs with no } \\
\text { requirement }\end{array}$} & $\begin{array}{l}\text { (1) Pre-service training with no re- } \\
\text { quirement }\end{array}$ & $\begin{array}{l}\text { Angeli and Jaipal-Jamani 2018; Chambers and } \\
\text { Carbonaro 2003; Hadjiachilleos et al. 2013; } \\
\text { Jaipal-Jamani and Angeli 2017; Kaya et al. } \\
\text { 2017; Major et al. 2011; Major et al. } 2014 .\end{array}$ \\
\hline & $\begin{array}{l}\text { (1) In-service training with no re- } \\
\text { quirement }\end{array}$ & $\begin{array}{l}\text { Alimisis 2019; Bredenfeld and Leimbach 2010; } \\
\text { Caballero-González and Muñoz-Repiso } \\
\text { 2017; Goodale 2013; Hamner et al. 2016; } \\
\text { Kay and Moss 2012; Riedo et al. 2012; } \\
\text { Scaradozzi et al. 2019; Santos et al. 2016; } \\
\text { von Wangenheim et al. } 2017\end{array}$ \\
\hline & $\begin{array}{l}\text { (1) Mixed teacher-status training } \\
\text { with no requirement }\end{array}$ & Alimisis 2014; Zhou et al. 2015. \\
\hline \multirow[t]{3}{*}{$\begin{array}{l}\text { Teacher training with } \\
\text { a final project } \\
\text { requirement }\end{array}$} & $\begin{array}{l}\text { (2) Pre-service training with a final } \\
\text { project requirement }\end{array}$ & $\begin{array}{l}\text { Kim et al. 2015; Kim et al. 2012; Kucuk and } \\
\text { Sisman 2018; Nagchaudhuri and Mitra } \\
\text { 2007; Sisman and Kucuk } 2019\end{array}$ \\
\hline & $\begin{array}{l}\text { (2) In-service training with a final } \\
\text { project requirement (creation } \\
\text { ofteaching material) }\end{array}$ & $\begin{array}{l}\text { Bers et al. 2013; Castro et al. 2018; Gilkes } \\
\text { et al. 2014; Negrini } 2019 .\end{array}$ \\
\hline & $\begin{array}{l}\text { (2) Mixed teacher-status training } \\
\text { with a final project requirement }\end{array}$ & Agatolio et al. 2017; Alimisis et al. 2009. \\
\hline \multirow[t]{2}{*}{$\begin{array}{l}\text { Teaching practice } \\
\text { requirement }\end{array}$} & $\begin{array}{l}\text { (3) In-service training with a teach- } \\
\text { ing practice requirement }\end{array}$ & $\begin{array}{l}\text { Conchinha 2015; Hodges et al. 2016; Hynes } \\
\text { and Dos Santos 2007; Leonard et al. 2017; } \\
\text { Sullivan and Moriarty } 2009 .\end{array}$ \\
\hline & $\begin{array}{l}\text { (3) Pre-service training with a } \\
\text { teaching practice requirement }\end{array}$ & $\begin{array}{l}\text { Bers et al. 2002; Bers and Portsmore 2005; } \\
\quad \text { Verner 2013. }\end{array}$ \\
\hline
\end{tabular}

2012; Kim et al. 2015). Participants may also be asked to create a pedagogical project to be applied in the classroom (Castro et al. 2018), design their own robotics instructional materials for use in their future classes (Bers et al. 2013), design worksheets that combine robotics and other subjects on the curriculum (Gilkes et al. 2014) or develop multi-disciplinary didactic units and present them in class (Agatolio et al. 2017). The training presented by Negrini (2019) moves a step further by suggesting that a database of robotics materials could be created and a community could be built to allow trainees to stay in contact after the training program has ended. This database would help teachers find suitable ER materials since they would be able to exchange their own materials and opinions with their fellow teachers. Instead of designing instructional material, participants may be asked to design a robot for a specific educational use (Kucuk and Sisman 2018; Sisman and Kucuk 2019).

Finally, in our sample (see Table 2) there are eight ER training programs with a teaching practice requirement that highlight the importance of putting into practice the knowledge acquired on the program by applying it in a real educational context for preservice teachers or integrating it into daily teaching practice for in-service teachers. In the pre-service teacher training programs, the pre-service teachers are required to take part either by delivering the sessions or helping to deliver them. In Bers et al. (2002), pre-service early childhood teachers designed and delivered their own educational 
robotics sessions that integrated ER with other areas of the curriculum, while in Verner (2013) the participants helped to teach robotics to middle school and high school students in a technology laboratory. Moving a step further and involving students from other fields, in the study by Bers and Portsmore (2005) pre-service early childhood teachers collaborated with engineering students to create, implement and evaluate a curriculum in STEM subjects. In the case of in-service teacher training programs, on completion of their training participants were asked to deliver ER sessions to their students (Conchinha 2015; Hodges et al. 2016; Sullivan and Moriarty 2009).

\subsubsection{Duration of ER teacher training programs}

The duration of the training programs in the studies reviewed varies substantially, though information such as total training hours, hours attended, hours of teaching practice, time commitment and course credits (in the case of pre-service teacher training) is not always explicitly provided in the publications. Despite this lack of specific information on the duration of ER training programs, in this study we make a first attempt to classify relevant publications based on reported time commitment in the following categories; a) minimum duration (programs lasting one day only), b) short duration (programs lasting 2-5 days and/or 5-19 h), c) medium duration (programs lasting over 5 days and/or 20-39 h) d) long duration (programs lasting over 39 h), and e) no clear information about the duration of the program. Our results (see Table 3) show that 18 of the studies included in our review investigate short training programs that last less than 5 days and/or $19 \mathrm{~h}$. More specifically, six of these short duration programs last only one day. Even among these minimum-duration training programs, differences regarding the participants' time-commitment exist since the training session may last the whole day (Major et al. 2011), one afternoon (Nagchaudhuri and Mitra 2007), or three hours (Zhou et al. 2015).

An important question here is whether training programs of such a short duration are able to effectively address the research objectives set by researchers. The study by Zhou et al. (2015), for example, concluded that after taking part in the training sessions, the teachers perceived as positive their usefulness and the ease with which ER can be used. Doubt is cast, however, on whether these positive results are due to the three-hour training session itself or whether they derive from the teachers' prior experience with robotics. Similarly, the positive results reported in the study by Caballero-González and Muñoz-Repiso (2017) with regard to teachers' acceptance and motivation for using educational robotics could be due either to the one-day workshop itself or to the

Table 3 Duration of ER training programs

a) Minimum duration training programs (one day only)

b) Short-duration training programs (2-5 days and/or 5-19 h)

c) Medium-duration training programs (over 5 days and/or 20-39 h)

d) Long-duration training programs (over $39 \mathrm{~h}$ )

e) No clear information about the duration of the training program 
participants' enthusiasm with their first contact with robotics. To effectively examine the willingness and motivation of teachers for using ER resources in their teaching, longer training programs with requirements other than attendance and participation in workshop activities is necessary. Even a full-day workshop may lead the research community to question the comprehensiveness of such a training program and, therefore, the results of the corresponding research study.

\subsubsection{Trainer and trainee profile}

The participants in the training sessions in the studies we reviewed are either preservice teachers who attend a university course (15 studies) or in-service teachers who work in preschool, primary school or secondary school education (21 studies). Preschool teacher training is not as common as primary and secondary school teacher training. In the studies reviewed, only three training programs are held exclusively for preschool teachers (Bers et al. 2002; Bers et al. 2013; Caballero-González and MuñozRepiso 2017), while four training programs are held for preschool teachers as well as primary and secondary school teachers (Bers and Portsmore 2005; Castro et al. 2018; Negrini 2019; Scaradozzi et al. 2019). Even less common are training programs for special needs teaching staff since only two relevant studies were found. Training in the study by Conchinha (2015), for example, was designed for teachers of children with special educational needs, while that in the study by Agatolio et al. (2017) was designed for learning-support teachers from several disciplines. Some research studies provide further information about the participants' profiles. In the research studies we selected, the educational backgrounds of the participants differ substantially. In some studies, for example, the participants are ICT teachers/teacher candidates (von Wangenheim et al. 2017; Major et al. 2014; Major et al. 2011), while in others they are teachers of STEM subjects (Goodale 2013; Hodges et al. 2016; Kay and Moss 2012; Nagchaudhuri and Mitra 2007) or from a variety of subject areas (Gilkes et al. 2014; Hamner et al. 2016; Leonard et al. 2017; Riedo et al. 2012; Scaradozzi et al. 2019). The participants' prior experience with programming also varies from study to study. In Kay and Moss (2012), for example, most participants had little or no programming experience and were not very confident of their own ability to learn how to program a robot. Similarly, in Kaya et al. (2017) the participants had no prior programming or robotics experience. On the other hand, in Major et al. (2011) and Major et al. (2014) most trainees had programming experience, while in Zhou et al. (2015) most participants had experience in facilitating robotics clubs during the previous school year. Despite the heterogeneity in the participants' educational backgrounds and programming experience, several studies in our sample have one point in common, i.e. female participants tend to outnumber their male counterparts (Bers et al. 2013; Castro et al. 2018; Hadjiachilleos et al. 2013; Kim et al. 2012; Kim et al. 2015; Kucuk and Sisman 2018; Nagchaudhuri and Mitra 2007; Negrini 2019; Sisman and Kucuk 2019; von Wangenheim et al. 2017).

Some research studies also provide information about the trainers responsible for preparing and delivering the training programs. In the context of tertiary education, the trainer is usually a university professor with a background in ER, pedagogy and/or technology. Some programs have more than one trainer. In Angeli and Jaipal-Jamani (2018) and in Jaipal-Jamani and Angeli (2017), for example, there are two trainers with 
complementary profiles, one of whom is an instructional technology educator and the other is a science education lecturer. To further enrich the teachers' experience in ER training, the trainers-in-charge may invite experts in the field to conduct some of the training. For example, Kaya et al. (2017) invited a guest speaker specialized in engineering projects for minorities, including women, while, Hynes and Dos Santos (2007) invited experts from various fields to further add to the teachers' experience. As well as experts, training assistants also seem to play an important role in teacher training programs. In Chambers and Carbonaro (2003), a teaching assistant supported the participants with challenges or problems, while in Kay and Moss (2012), five Computer Science undergraduate assistants supported the participants during the lectures and hands-on periods. The assistants' role in this training is important since they make learning easier for participants and lessen their frustration with kits/equipment during a fast-paced training session (Gilkes et al. 2014). To portray the profiles of teacher trainers and their teams better, more information is needed about their background, expertise and role in the training program.

\subsubsection{ER pedagogical approaches}

As well as learning about ER and gaining confidence with ER resources, the teachers need to become familiar with pedagogical approaches to ER activities and the implementation of the curriculum in school contexts. When examining the studies in our sample, we found that not all training programs focus on pedagogical approaches and relevant theories. Although some studies refer to some teaching approaches in the introductions to their articles and perhaps also in the theoretical framework, they do not clarify whether the training itself or the curriculum were based on the approaches we have previously mentioned. In Kim et al. (2015), for example, the authors refer to several teaching approaches (e.g. project-based learning, student-centered approach, etc.). However, they do not state explicitly which learning theory their teacher training program is based on. Finally, several studies in our sample were clearly not based on any pedagogical approach or theory (Caballero-González and Muñoz-Repiso 2017; Hamner et al. 2016; Kay and Moss 2012; Major et al. 2011; Riedo et al. 2012; Gilkes et al. 2014; Nagchaudhuri and Mitra 2007), since none of the sections in those articles refers to learning theories or pedagogical approaches.

The teacher training programs that are based on a pedagogical approach or theory are usually based on constructivist/constructionist pedagogy (Agatolio et al. 2017; Alimisis et al. 2009; Alimisis 2014; Alimisis 2019; Bers et al. 2002; Bers and Portsmore 2005; Castro et al. 2018; Chambers and Carbonaro 2003; Major et al. 2014; Negrini 2019; Scaradozzi et al. 2019; Sisman and Kucuk 2019). Participants in a constructionist learning environment are able to experience for themselves instruction and meaningful learning within a hands-on, constructive, collaborative and active environment (Chambers and Carbonaro 2003). For example, in Bers et al. (2002) and Bers and Portsmore (2005), the courses were based on the four tenets of constructionism, i.e. learning by design, using objects to learn with, identifying powerful ideas, and understanding the importance of self-reflection. The 5-E Model (Engage, Explore, Explain, Elaborate and Evaluate) presented in the study by Hynes and Dos Santos (2007) was also based on a constructivist philosophy of learning. Another pedagogical approach implemented in several studies in our sample is the 
inquiry-based method (Hadjiachilleos et al. 2013; Hodges et al. 2016; Jaipal-Jamani and Angeli 2017; Zhou et al. 2015). As Zhou et al. (2015) asserted, an inquiry-based approach addresses the needs of a diverse student population and enables students to take charge of their learning experiences. Also common in the teacher training programs in our sample are the project-based learning approach (Alimisis 2019; Alimisis et al. 2009; Negrini 2019), the discovery-based learning approach (Sullivan and Moriarty 2009) and learning by design (Alimisis et al. 2009). Some training programs were also based on the Next Generation Science Standards (NGSS), the Engineering Design Process (Goodale 2013; Kaya et al. 2017) or the innovative didactic methodologies of Digital Storytelling and Classroom Debate (Scaradozzi et al. 2019). Finally, two studies were based on the Technological Pedagogical Content Knowledge (TPCK) framework (Bers et al. 2013; Castro et al. 2018).

\subsection{Research question 2: What best practices for ER teacher training programs are documented in the literature?}

Our review identifies the best practices in ER teacher training. These are divided into the five following categories: Collaboration, materials, pedagogy, practice and feedback/support (see Table 4).

\subsubsection{Best practices: Collaboration}

The publications in our sample underline the importance of collaboration among the training participants. In the study by Agatolio et al. (2017), the teachers collaborated throughout the training program on developing the final project while in the study by Scaradozzi et al. (2019), the trainees shared artefacts, compared different solutions and taught each other how to solve various types of problems. Similarly, in the study by Zhou et al. (2015), the program incorporated a discussion session for sharing ideas on multidisciplinary ER activities. Kucuk and Sisman (2018) recommended creating a non-competitive atmosphere for the program without panic or stress. The participants were allowed to work individually or in pairs according to their preference (Bredenfeld and Leimbach 2010). In the study by Conchinha (2015), some teachers worked together in the same school and chose to collaborate on developing activities for their students. In other studies, the participants collaborated after completing their training. Hynes and Dos Santos (2007) stressed the importance of exchanging feedback when implementing ER activities, so they held afternoon sessions for their teachers where they could discuss successful strategies, resources, materials and solutions to implementation challenges. Hynes and Dos Santos (2007) asserted that it would be useful for teachers to observe each other teaching and to share teaching classroom styles, approaches, struggles and successes. In the same vein, Kim et al. (2015) suggested that giving teachers the opportunity to observe how other teachers integrate STEM content into robotics activities may also help teachers improve their own lesson plans. Collaboration among teachers could also be expanded even further by building a community of teachers. Some researchers highlighted the importance of building this community to make training programs more effective (Hamner et al. 2016). Others suggested that the community could be 
Table 4 Best practices summary

\begin{tabular}{|c|c|}
\hline Categories & Best practices \\
\hline Collaboration & $\begin{array}{l}\text { - To encourage collaboration among participants to develop a final project. } \\
\text { - To create a teacher community or network at the EU level to facilitate sharing among } \\
\text { educators. } \\
\text { - To hold afternoon sessions immediately after implementing ER activities in the } \\
\text { classroom to enable participants to discuss and exchange opinions and experiences. } \\
\text { - To observe the teaching performance of fellow trainees in order to share teaching styles, } \\
\text { approaches, struggles and successes and to incorporate STEM content into robotics } \\
\text { activities. } \\
\text { - To share artefacts, solutions and ideas on multidisciplinary ER activities. } \\
\text { - To create a non-competitive atmosphere among trainees with no panic or stress. }\end{array}$ \\
\hline Practice & $\begin{array}{l}\text { - To practice a specific exercise with robots and software and implement technical } \\
\text { knowledge with hands-on work involving assembly and programming. } \\
\text { - To ensure sufficient time is available on the program to enable participants to become } \\
\text { familiar with the resources, do programming and assembling activities, and do graded } \\
\text { exercises. } \\
\text { - To incorporate their ER activities into their schools or participate in outreach robotics } \\
\text { activities. }\end{array}$ \\
\hline Materials & $\begin{array}{l}\text { - To make robotics kits available for classroom teaching and provide trainees with the } \\
\text { equipment they used in their training so that they can use it in their own classes. } \\
\text { - To provide participants with teaching materials. } \\
\text { - To enable participants to use their training time to design ER teaching materials and later } \\
\text { implement them in their own classroom. } \\
\text { - To create a database of ER activities. }\end{array}$ \\
\hline Pedagogy & $\begin{array}{l}\text { - To instruct trainees in the pedagogical frameworks for implementing ER activities, } \\
\text { innovative didactic methodologies, best examples of ER activities, and integrating ER } \\
\text { into various fields. } \\
\text { - To teach participants how to deal with issues such as classroom management in ER } \\
\text { activities. }\end{array}$ \\
\hline $\begin{array}{l}\text { Feedback and } \\
\text { support }\end{array}$ & $\begin{array}{l}\text { - To provide participants with researcher feedback on the lesson plans they create during } \\
\text { the training program. } \\
\text { - To provide ongoing teacher support by observing the participants' classes and assisting } \\
\text { in the activities. }\end{array}$ \\
\hline
\end{tabular}

expanded to the EU level (Alimisis et al. 2009) or explained that it would help to promote communication, collaborative work and sharing among researchers, teachers and learners (Alimisis 2014).

\subsubsection{Best practices: Teaching materials}

Another best practice reported in the publications in our sample is to provide teachers with materials for classroom use after the end of the training program. Alimisis et al. (2009) suggested that teachers need a sufficient number robotics kits available in order to use robotics in their classroom teaching, while Riedo et al. (2012) asserted that teachers need to be given the equipment they used in the training for free so that they can apply in their classrooms what they had learned during their training. It has also been suggested that teachers should take the materials they used in training to school to showcase them to their students and colleagues (Kay and Moss 2012). Providing the participants with teaching materials is also good practice because it facilitates the future 
application of ER activities in the classroom (Castro et al. 2018; Hamner et al. 2016; Negrini 2019) since teachers do not have much time in the regular school week to devote to planning (Hamner et al. 2016). In fact, Hamner et al. (2016) suggested that teachers should use their training time to design the ER activities they will later implement in class. In the study by Negrini (2019), a database of educational robotics activities was created by the teachers themselves, which they later applied in their own classrooms. First they tested the activities with their own students and then shared them with their fellow trainees.

\subsubsection{Best practices: Pedagogy}

Best practices in ER teacher training also involve instructing trainees in the pedagogical aspects of ER (Kim et al. 2012). In the program presented in the study by Castro et al. (2018), the training went much further than using robots in educational settings since the teachers were instructed in pedagogical and learning theories, shown best cases of ER activities, and asked to develop a didactic project. Similarly, in the program presented in the study by Scaradozzi et al. (2019), the participants were given instruction in the pedagogical frameworks behind the implementation of ER activities as well as in innovative didactic methodologies. Kucuk and Sisman (2018) recommended providing information about ER pedagogical approaches and integrating ER into the various areas of the curriculum. In addition to being given technical and pedagogical knowledge, teachers should also learn how to deal with issues that are likely to come up in their future classes, e.g. how to manage the classroom during ER activities (Hynes and Dos Santos 2007).

\subsubsection{Best practices: Practice}

Another good practice is to encourage teachers to put the technical and pedagogical knowledge they have acquired on the training program into practice. Researchers recommend that teachers should, on the one hand, put their technical knowledge into practice through hands-on work involving assembly and programming (Kim et al. 2015) and concrete exercises in using robots and software themselves (Agatolio et al. 2017). On the other hand, they should also have the opportunity to use the new teaching resources and materials by implementing ER activities into their classrooms (Hynes and Dos Santos 2007) or participating in outreach robotics activities (Gilkes et al. 2014). With regard to technical practice, ER training activities should be of graded difficulty, beginning with simple exercises and with the level of difficulty gradually increasing (Negrini 2019). Teachers should also be given sufficient time for programming and assembling during training (Goodale 2013) and for familiarizing themselves with the equipment (Agatolio et al. 2017; Hamner et al. 2016).

\subsubsection{Best practices: Feedback and support}

Finally, another good practice in ER teacher training programs is to receive support from the instructors/researchers during and after the training program. Negrini (2019) recommended that the research team should regularly be invited to classes to observe the activities teachers have planned and even to help out. This would give the 
researchers an overview of what the teachers are doing and what their needs are after the program has officially ended (Negrini 2019). In line with this idea, von Wangenheim et al. (2017) stressed that ongoing teacher support is needed throughout the training program. Hamner et al. (2016) also recommended that researchers should give teachers feedback on the lesson plans they create in the training sessions.

\section{Conclusions \& Recommendations}

The main aims of this study were to examine the characteristics of ER teacher training programs and provide recommendations on the content, structure and implementation of future ER teacher training programs and research studies (see Table 5). First we examined the characteristics of the studies and then made recommendations for ER teacher training and research.

One of the main conclusions from this study is that a substantial number of training programs do not set any requirements for their completion. However, setting requirements such as designing robots, creating programs, designing instructional materials or doing teaching practice would ensure that participants would acquire the learning they

Table 5 Recommendations for the design of future ER teacher training programs and research

Recommendations for future ER research design
Recommendations for future ER teacher training programs
Conduct further research in ER teacher training for teachers of children with special educational needs and teachers in preschool education.

Implement a well-documented teaching methodology founded on pedagogical theory and explain its implementation explicitly in the description of the training program.

Strengthen the description of the ER teacher training program by providing information on the precise duration of the program and the profiles of the trainers (background, expertise and functions).

Extend the sample and duration of the intervention in order to increase the representativeness and generalizability of the research results.

Improve the generalizability of the results by implementing pilot studies and/or control groups, using rigorous (quantitative and qualitative) research methods and reliable and validated data collection instruments.

Assess the effectiveness of the teacher training program by measuring the participants' competence based on their projects or their implementation of ER activities in a real teaching context.
Promote the exchange of ideas and materials between teachers during and/or after the training program.

Incorporate pedagogical as well as technical aspects into ER teacher training.

Provide teachers with the robotics kits they used on their training program (if available) so that they can use them in the classroom.

Give teachers the opportunity to put their technical and/or pedagogical knowledge into practice during the training program.

Create a positive learning atmosphere by promoting collaboration during the training program.

Ensure teachers receive support from their training instructors/researchers both during and after their training program.

Adjust the pace and/or content of the training program to the participants' needs and preferences. 
need and that the effectiveness of the training program or other variables would be effectively measured. For research studies whose aim is to measure the effect of ER teaching methods or ER teacher training models, a final project or teaching practice requirement would make measuring the effect easier, increase the reliability of the research, and improve the generalizability of the results. We therefore recommend setting requirements to complete the training program and including these requirements in the research study design. As was suggested by Pedersen et al. (2020) when they studied the effect of commercially available ER products, ER research design needs improving. This can be achieved by implementing pilot studies and/or control groups, using rigorous research methods (both quantitative and qualitative), and using reliable and validated data collection instruments. Training completion requirements such as designing a robot, creating a program, designing instructional materials or doing teaching practice could function as data collection sources and/or instruments and thus improve the design of the research study.

Another important conclusion concerns the duration of the training programs, a considerable number of which are relatively short. The short-term nature of K12 robotics studies was also reported by Bascou and Menekse (2016). Moreover, the precise duration of the programs is often unclear since measurement methods differ from context to context, e.g. terms such as half-day, module-long, and hour (to refer either to a teaching duration or a time interval of $60 \mathrm{~min}$ ) vary from country to country and probably from institution to institution. The descriptions of the training programs included in this study also lack information about the required time commitment (the total number of training hours, attendance hours, teaching practice hours, etc.) and the academic or professional development (PD) credits awarded by the programs. We therefore suggest strengthening the descriptions of the training programs with details of the total number of training hours, attendance hours, teaching practice hours etc. We also recommend increasing the duration of the training programs and improving the reliability of the findings by conducting longitudinal research studies.

From our analysis of the profile of trainees, we also conclude that there is a limited number of ER teacher training studies for preschool teachers and teachers of children with special educational needs. Moreover, the participants' subject area and prior experience with programming differ greatly from study to study. However, a common feature is that most participants are female. The tendency for female ER teacher training participants to outnumber their male counterparts may be explained by the greater number of females in education and/or women's greater interest in learning about ER resources and pedagogies. The fact that numerous ER training programs address teachers with different subject areas, including those whose school subjects are not conventionally linked to technology, highlights the interdisciplinarity of ER. With regard to the profile of the trainers, the studies often lack explicit information about their background, expertise or organization. We suggest that in future ER teacher training research should be conducted on teachers of children with special educational needs and preschool teachers and that the training descriptions should be reinforced with the trainers' profile. We also recommend using gender-balanced random sampling with an appropriate sample size in order to increase the representativeness and generalizability of the research results. As was also reported in Pedersen et al. (2020), researchers' access to samples in educational institutions should be facilitated to achieve this. 
Throughout the robotics evolution process, a wide range of ER resources have become available to the educational community, thus facilitating the implementation of ER activities. The robotics evolution is also reflected in ER teacher training since the number of ER teacher training research studies has increased over the last few years. Two of the training studies contained in this review were published between 2000 and 2004, five were published between 2005 and 2009, 11 between 2010 and 2014, while 20 have been published in the last five years (2015-2019). ER teacher training programs are becoming increasingly important in educational research. However, researchers do not always focus on the pedagogical approach or base their programs on learning theory. Our results show that seven studies clearly do not base the content or structure of their training program on any pedagogical approach or learning theory. Those that do are mainly based on constructivist/constructionist pedagogy, the inquirybased approach or project-based learning. Our results are partially in line with those of Altin and Pedaste (2013), who report that the most popular methods in teaching robotics are problem-based, constructivist and competition-based. From the above, we conclude that ER teacher training programs should implement a well-documented teaching methodology based on pedagogical theory, justify their choice of methodology, and explicitly explain in their program description how it will be implemented.

As well as studying the characteristics of ER training programs, in this this review we also make recommendations for future teacher training programs (see Table 5). Our recommendations are built on the best practices encountered in the studies we have reviewed (see Section 3.2). First we recommend encouraging teachers' exchange of views and/or materials during and/or after their training. Teachers can benefit from sharing ideas and instructional materials during the program and on their follow-up teaching practice. They would also greatly benefit from observing their fellow training participants on their teaching practice. At the end of the program, we also suggest building a network of public (state) school teachers who have attended ER teacher training programs and are currently applying ER activities in their schools. This teachers' network could be organized at the local level, be coordinated by the ministries of the various countries involved, and support its members by holding events and seminars. These events and seminars would facilitate the exchange of teaching materials between teachers and enable the community to discuss and solve any common difficulties they have encountered in their educational contexts. We also advise providing the educational institutions where the trainees are employed with a suitable number of ER resources for classroom use, especially those that are used on the training program since the teachers will already know how to use them. Educational institutions should plan the allocation of ER resources among their classes carefully to ensure they have a suitable number of robotics kits for their groups of students. If an insufficient number of robotics kits are available for all schools, we encourage schools to share their resources with their neighboring institutions under the supervision of local ministries or services. We also recommend ensuring that teachers have instructional materials available for classroom use after their training. These instructional materials could be provided by the program instructors or designed during their training by the participants themselves. As well as providing instruction in how to use robotics resources and/or programming, the ER training program should also be pedagogically oriented. The participants should be familiar with pedagogical aspects associated with classroom implementation, such as the pedagogical frameworks behind the implementation of the 
ER activities, innovative didactic methodologies for integrating ER into the various fields, and the classroom management of ER activities. We also advise giving teachers the opportunity to put their technical and/or pedagogical knowledge into practice by conducting hands-on work involving assembly and programming, conducting specific exercises on the use of robots and software, and conducting ER activities in their schools or outreach educational programs. We also recommend adapting the pace and/ or content of training to the participants' needs and preferences, since the participants are teachers themselves and are able to identify in which areas they need more help and which areas will be more useful for their educational context and level. Finally, since the participants' first contact with ER can be quite demanding, we recommend that they should be given continuous support by the training instructors/researchers both during and after their training program when they are incorporating their ER activities into their school context. This ongoing support could last for either a semester or a school year depending on the teacher's profile and his or her performance in the training sessions. The support could be technical or related to instructional materials or classroom management issues depending on the individual teacher's profile and needs.

The above recommendations should contribute to the content, structure and implementation of future ER teacher training programs and the design of research studies (Table 5). One limitation of this review, however, is that it was based on the limited number of teacher training interventions documented in the current literature. Since most ER teacher training programs are conducted outside the research community, these are not often scientifically documented. It would be interesting for future research to examine the effectiveness of training programs based on the recommendations outlined in this paper and make further suggestions for improving the research on training programs. We also suggest assessing trainees based on implementations of ER activities in real teaching contexts, since classroom data would help to create a comprehensive study of the effectiveness of the teacher training programs delivered. Finally, future research is also needed to further examine the reliability and generalizability of the results of ER teacher training research.

Supplementary Information The online version contains supplementary material available at https://doi.org/ 10.1007/s10639-020-10377-z.

Acknowledgements This project has received funding from the European Union's Horizon 2020 research and innovation programme under the Marie Skłodowska-Curie grant agreement No. 713679. This paper has been possible with the support of the Universitat Rovira i Virgili (URV) and Banco Santander. We would also like to thank the reviewers for their helpful comments.

Availability of data and materials The datasets analyzed during the current study are available from the corresponding author on reasonable request.

Code availability Not applicable.

Authors' contributions All authors contributed extensively to the work presented in this paper and approved the final manuscript. All authors contributed to the study design and methods, synthesized and interpreted data. VEG and MU contributed to the design of the data collection instrument and DS wrote the 
manuscript as part of her PhD thesis with significant input from VEG and MU. All authors discussed the results and implications and commented on the manuscript at all stages.

Funding This project has received funding from the European Union's Horizon 2020 research and innovation programme under the Marie Skłodowska-Curie grant agreement No. 713679. This paper has been possible with the support of the Universitat Rovira i Virgili (URV) and Banco Santander.

\section{Compliance with ethical standards}

Conflicts of interest/competing interests The authors declare that they have no conflict of interest.

Abbreviations DT, digital technologies; STEM, Science, technology, engineering, and mathematics; $E R$, educational robotics

Open Access This article is licensed under a Creative Commons Attribution 4.0 International License, which permits use, sharing, adaptation, distribution and reproduction in any medium or format, as long as you give appropriate credit to the original author(s) and the source, provide a link to the Creative Commons licence, and indicate if changes were made. The images or other third party material in this article are included in the article's Creative Commons licence, unless indicated otherwise in a credit line to the material. If material is not included in the article's Creative Commons licence and your intended use is not permitted by statutory regulation or exceeds the permitted use, you will need to obtain permission directly from the copyright holder. To view a copy of this licence, visit http://creativecommons.org/licenses/by/4.0/.

\section{References}

Agatolio, F., Pivetti, M., Di Battista, S., Menegatti, E., \& Moro, M. (2017). A training course in educational robotics for learning support teachers. In D. Alimisis, M. Moro, \& E. Menegatti (Eds.), Educational robotics in the makers era (pp. 43-57). Cham: Springer.

Alimisis, D. (2014). Educational robotics in teacher education: An innovative tool for promoting quality education. In L. Daniela, I. Lūka, L. Rutka, \& I. Žogla (Eds.), Teacher of the 21st century: Quality education for quality teaching (pp. 14-27). Cambridge: Cambridge Scholars Publishing.

Alimisis, D. (2019). Teacher training in educational robotics : The ROBOESL project paradigm. Technology, Knowledge and Learning, 24(2), 279-290. https://doi.org/10.1007/s10758-018-9357-0.

Alimisis, D., Frangou, S., \& Papanikolaou, K. (2009). A constructivist methodology for teacher training in educational robotics: The TERECoP course in Greece through trainees eyes. In 2009 ninth IEEE international conference on advanced learning technologies (pp. 24-28). Riga: IEEE. https://doi.org/10. 1109/ICALT.2009.86.

Altin, H., \& Pedaste, M. (2013). Learning approaches to applying robotics in science education. Journal of Baltic Science Education, 12(3), 365-377.

Angeli, C., \& Jaipal-Jamani, K. (2018). Preparing pre-service teachers to promote computational thinking in school classrooms. In M. Khine (Ed.), Computational thinking in the STEM disciplines (pp. 127-150). Cham: Springer.

Bascou, N, A. \& Menekse, M. (2016). Robotics in K-12 Formal and Informal Learning Environments: A Review of Literature. In 2016 ASEE Annual Conference and Exposition. New Orleans, USA. https://doi. org/10.18260/p.26119

Benitti, F. B. V. (2012). Exploring the educational potential of robotics in schools: A systematic review. Computers \& Education, 58(3), 978-988. https://doi.org/10.1016/j.compedu.2011.10.006.

Bers, M. U., \& Portsmore, M. (2005). Teaching partnerships : Early childhood and engineering students teaching math and science through robotics. Journal of Science Education and Technology, 14(1), 59-73. https://doi.org/10.1007/s10956-005-2734-1.

Bers, M. U., Ponte, I., Juelich, C., Viera, A., \& Schenker, J. (2002). Teachers as designers: Integrating robotics in early childhood education. Information Technology in Childhood Education Annual, 2002(1), 123145 . 
Bers, M. U., Seddighin, S., \& Sullivan, A. (2013). Ready for robotics : Bringing together the T and E of STEM in early childhood teacher education. Journal of Technology and Teacher Education, 21(3), 355377.

Bredenfeld, A. H., \& Leimbach, T. (2010). The Roberta Initiative. In Proceedings of SIMPAR 2010 Workshops international conference on simulation. Darmstadt: Modeling and Programming for Autonomous Robots.

Caballero-González, Y. A., \& Muñoz-Repiso, A. G. V. (2017). Development of computational thinking and collaborative learning in kindergarten using programmable educational robots: A teacher training experience. In Proceedings of the 5th International Conference on Technological Ecosystems for Enhancing Multiculturality (TEEM 2017). New York: Association for Computing Machinery. https://doi.org/10. $1145 / 3144826.3145353$.

Castro, E., Cecchi, F., Salvini, P., Valente, M., Buselli, E., Menichetti, L., \& Calvani, A. (2018). Design and impact of a teacher training course, and attitude change concerning educational robotics. International Journal of Social Robotics, 10(5), 669-685. https://oi.org/10.1007/s12369-018-0475-6.

Chambers, J. M., \& Carbonaro, M. (2003). Designing, developing, and implementing a course on LEGO robotics for technology teacher education. Journal of Technology and Teacher Education, 11(2), 209241.

Committee on Industry, Research and Energy, (2019). Report on a comprehensive European industrial policy on artificial intelligence and robotics. Resource document. http://www.europarl.europa.eu/doceo/ document/A-8-2019-0019 EN.pdf. Accessed 30 September 2019.

Conchinha, C. (2015). Robots \& NEE: Learning by playing with robots in an inclusive school setting. In 2015 International Symposium on Computers in Education (SIIE) (pp. 86-91). Setubal: Association for Computing Machinery. https://doi.org/10.1109/SIIE.2015.7451654.

Gilkes, T., Radix, C., \& Ringis, D. (2014). A study of robotics in caribbean education. In 2014 IEEE Frontiers in Education Conference (FIE) Proceedings (pp. 1-5). Madrid: IEEE. https://doi.org/10.1109/FIE.2014. 7044458.

Goodale, T., \& A. (2013). The Influence of a ROV themed engineering design workshop on in-service teacher self- efficacy. In 2013 IEEE integrated STEM Education Conference (ISEC) (pp. 1-5). Princeton: IEEE. https://doi.org/10.1109/ISECon.2013.6525202.

Hadjiachilleos, S., Avraamidou, L., \& Papastavrou, S. (2013). The use of Lego Technologies in Elementary Teacher Preparation. Journal of Science Education and Technology, 22(5), 614-629.

Hamner, E., Cross, J., \& Zito, L. (2016). Training teachers to integrate engineering into non-technical middle school curriculum. In 2016 IEEE Frontiers in education conference (FIE) (pp. 1-9). Erie: IEEE. https:// doi.org/10.1109/FIE.2016.7757528.

Hodges, C., Gale, J., \& Meng, A. (2016). Teacher self-efficacy during the implementation of a problem-based science curriculum. Contemporary Issues in Technology and Teacher Education, 16(4), 434-451.

Hynes, M. M., \& Dos Santos, A. (2007). Effective teacher professional development: Middle-school engineering content. International Journal of Engineering Education, 23(1), 24-29.

Jaipal-Jamani, K., \& Angeli, C. (2017). Effect of robotics on elementary Preservice teachers' self-efficacy, science learning, and computational thinking. Journal of Science Education and Technology, 26(2), 175192.

Kay, J. S., \& Moss, J. G. (2012). Using robots to teach programming to K-12 teachers. In 2012 Frontiers in Education Conference Proceedings (pp. 1-6). Seattle: IEEE. https://doi.org/10.1109/FIE.2012.6462375.

Kaya, M. E., Newley, A., Deniz, H., \& Yesilyurt, E. (2017). Improving pre-service elementary teachers' nature of engineering views with the use of EV3 robotics. In 2017 ASEE Annual Conference \& Exposition. Columbus: American Society for Engineering Education. https://doi.org/10.18260/1-2\% 2D\%2D27698.

Kim, H., Choi, H., Han, J., \& So, H. J. (2012). Enhancing teachers' ICT capacity for the 21 st century learning environment: Three cases of teacher education in Korea. Australasian Journal of Educational Technology, 28(6), 965-982.

Kim, C., Kim, D., Yuan, J., Hill, R. B., Doshi, P., \& Thai, C. N. (2015). Robotics to promote elementary education pre-service teachers' STEM engagement, learning, and teaching. Computers and Education, 91, 14-31. https://doi.org/10.1016/j.compedu.2015.08.005.

Kitchenham, B.. (2004). Procedures for performing systematic reviews. Joint technical report, Keele University. Resource document. http://www.inf.ufsc.br/ aldo.vw/kitchenham.pdf. Accessed 30 September 2019.

Kucuk, S., \& Sisman, B. (2018). Pre-service teachers' experiences in learning robotics design and programming. Informatics in Education, 17(2), 301-320. https://doi.org/10.15388/infedu.2018.16. 
Leonard, J., Unertl, A., Barnes-Johnson, J., Stubbe, C. R., Mitchell, M., \& Ingraham, L. (2017). Developing teachers' computational thinking beliefs and engineering practices through game design and robotics. In Proceedings of the 39th Annual Meeting of the North American Chapter of the International Group for the Psychology of Mathematics Education. Indianapolis: Hoosier Association of Mathematics Teacher Educators.

Major, L., Kyriacou, T., \& Brereton, P. (2011). Experiences of prospective high school teachers using a programming teaching tool. In Proceedings of the 11th Koli Calling International Conference on Computing Education Research (pp. 126-131). New York: Association for Computing Machinery. https://doi.org/10.1145/2094131.2094161.

Major, L., Kyriacou, T., \& Brereton, P. (2014). The effectiveness of simulated robots for supporting the learning of introductory programming: A multi-case case study. Computer Science Education, 24(2-3), 193-228. https://doi.org/10.1080/08993408.2014.963362.

Nagchaudhuri, A., \& Mitra, M. (2007). Technology education in K 12: Revelations from designing and delivering a robotics lesson plan for pre service teachers paper. Honolulu: Annual Conference \& Exposition.

Negrini, L. (2019). Teacher training in educational robotics. In W. Lepuschitz, M. Merdan, G. Koppensteiner, R. Balogh, \& D. Obdržálek (Eds.), Advances in intelligent systems and computing. Cham: Springer.

Nugent, G. C., Barker, B. S., \& Grandgenett, N. (2012). The impact of educational robotics on student STEM learning, attitudes, and workplace skills. In B. S. Barker, G. Nugent, N. Grandgenett, \& V. I. Adamchuk (Eds.), Robotics in K-12 education: A new technology for learning (pp. 186-203). Hershey, PA: IGI Global.

Pedersen, B. K. M. K., Larsen, J. C., \& Nielsen, J. (2020). The effect of commercially available educational robotics: A systematic review. In M. Merdan, W. Lepuschitz, G. Koppensteiner, R. Balogh, \& D. Obdržálek (Eds.), Advances in intelligent systems and computing. Cham: Springer.

Riedo, F., Freire, M., Bonani, M., \& Mondada, F. (2012). Involving and training public school teachers in using robotics for education. In 2012 IEEE Workshop on Advanced Robotics and its Social Impacts (ARSO) (pp. 19-23). Munich: IEEE. https://doi.org/10.1109/ARSO.2012.6213392.

Santos, I. M., Ali, N., Khine, M. S., Hill, A., Abdelghani-Kassem, U., \& Al-Qahtani, A. (2016). Teacher perceptions of training and intention to use robotics. In 2016 IEEE Global Engineering Education Conference (EDUCON) (pp. 798-801). Abu Dhabi: IEEE. https://doi.org/10.1109/EDUCON.2016. 7474644.

Scaradozzi, D., Screpanti, L., Cesaretti, L., Storti, M., \& Mazzieri, E. (2019). Implementation and assessment methodologies of Teachers' training courses for STEM activities. Technology, Knowledge and Learning, 24(2), 247-268. https://doi.org/10.1007/s10758-018-9356-1.

Sisman, B., \& Kucuk, S. (2019). Educational robotics course: Examination of educational potentials and preservice teachers' experiences. International Journal of Research in Education and Science, 5(2), 510531.

Spolaôr, N., \& Benitti, F. B. V. (2017). Robotics applications grounded in learning theories on tertiary education: A systematic review. Computers and Education, 112, 97-107. https://doi.org/10.1016/j. compedu.2017.05.001

Sullivan, F. R., \& Moriarty, M. A. (2009). Robotics and discovery learning: Pedagogical beliefs, teacher practice, and technology integration. Journal of Technology and Teacher Education, 17(1), 109-142.

Taylor, P., \& C. (2016). Why is a STEAM curriculum perspective crucial to the 21st century? In 14th Annual conference of the Australian Council for Educational Research. Brisbane: Murdoch University Research Repository. http://researchrepository.murdoch.edu.au/id/eprint/37950.

Tochácek, D., Lapes, J., \& Fuglík, V. (2016). Developing technological knowledge and programming skills of secondary schools students through the educational robotics projects. Procedia-Social and Behavioral Sciences, 217, 377-381. https://doi.org/10.1016/j.sbspro.2016.02.107.

Verner, I. (2013). Characteristics of student engagement in robotics. In K. Omar et al. (Eds.), Intelligent robotics systems: Inspiring the NEXT (pp. 181-194). Berlin: Springer.

von Wangenheim, A., von Wangenheim, C, G., Pacheco, F, S., Hauck, J, C, R., \& Ferreira, M, N, F. (2017). Motivating teachers to teach computing in middle school: A case study of a physical computing taster workshop for teachers. International Journal of Computer Science Education in Schools, 1(4). https://doi. org/10.21585/ijcses.v1i4.17.

Zhou, H., Yuen, T. T., Popescu, C., Guillen, A., \& Daviset, D. G. (2015). Designing teacher professional development workshops for robotics integration across elementary and secondary school curriculum. In 2015 International Conference on Learning and Teaching in Computing and Engineering (pp. 215-216). Taipei: IEEE. https://oi.org/10.1109/LaTiCE.2015.21. 
Publisher's note Springer Nature remains neutral with regard to jurisdictional claims in published maps and institutional affiliations.

\section{Affiliations}

\section{Despoina Schina ${ }^{1} \cdot$ Vanessa Esteve-González $^{1} \cdot$ Mireia Usart $^{1}$}

1 Department of Pedagogy, Applied Research Group in Education and Technology (ARGET), Universitat Rovira i Virgili, Tarragona, Spain 